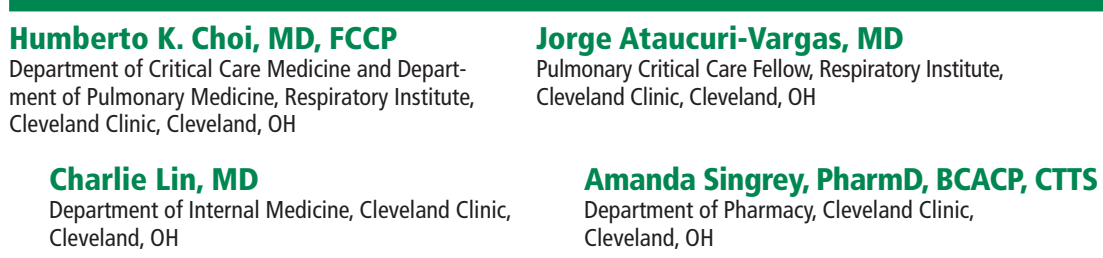

\title{
The current state of tobacco cessation treatment
}

\section{ABSTRACT}

Nicotine addiction and dependence is a chronic relapsing disease driven by addiction to nicotine. Proactive treatment for all tobacco users, regardless of their readiness to quit, is recommended. First-line tobacco cessation medications include nicotine replacement therapy, bupropion, and varenicline. Comprehensive treatment with behavioral interventions and pharmacologic therapy increases success rates of smoking cessation. Although there are many popular alternative treatments, they should not replace or delay the use of known effective therapies.

\section{KEY POINTS}

An individualized treatment for tobacco cessation is necessary and should be based on severity of nicotine dependence, probability of developing withdrawal symptoms, comorbidities, local resources, and patient preferences.

Comprehensive smoking cessation treatment provides counseling, assesses the patient's readiness to quit, offers treatment options, and arranges follow-up.

Evidence is lacking to support the use of smart phone "apps" for smoking cessation as monotherapy.

E-cigarettes are not used in tobacco cessation treatment as they can also cause nicotine addiction and other concerns.

doi:10.3949/ccjm.88a.20099
$\mathrm{T}$ OBACCO USE CONTINUES TO BE a major public health problem and a major risk factor for deaths from heart disease and several types of cancer such as lung, head and neck, and colorectal cancers. ${ }^{1}$ The prevalence of smoking has declined over the last 6 decades, to an all-time low of $13.7 \%$ in adults in $2018 .^{2}$ However, nicotine dependence is still considered a common and significant clinical problem.

A number of effective therapies exist, yet treating patients for tobacco cessation remains a challenge, not only for patients, but also for clinicians, who may not be aware of effective therapies available and may fail to offer treatment. Therefore, it is important for clinicians to familiarize themselves with treatment options they can offer to every smoker.

In this article, we review behavioral interventions and pharmacotherapy to treat nicotine dependence associated with tobacco use. We also discuss the role of e-cigarettes.

\section{A PROACTIVE APPROACH TO TOBACCO CESSATION}

The 2008 US Public Health Service guidelines outlined an evidence-based behavioral intervention to manage tobacco treatment in primary care called the 5-A (ask, advise, assess, assist, and arrange) framework, which is still used today. ${ }^{3}$ Its aim is to identify every smoker, provide counseling, assess readiness to quit, offer treatment options, and arrange follow-up.

Nicotine dependence is a chronic, relapsing disease driven by addiction to nicotine. A proactive approach is needed, offering treatment to all smokers regardless of their level of readiness to quit. Treatment should be in- 
TABLE 1

\section{The Heaviness of Smoking Index}

How many cigarettes do you smoke a day?

\section{Score}

$\begin{array}{ll}10 \text { or fewer } & 0 \\ 11-20 & 1 \\ 21-30 & 2 \\ 31 \text { or more } & 3\end{array}$

How soon after waking up do you smoke your first cigarette of the day?

$\begin{array}{ll} & \text { Score } \\ 60 \text { minutes } & 0 \\ 31-60 \text { minutes } & 1 \\ 6-30 \text { minutes } & 2 \\ \text { Within } 5 \text { minutes } & 3\end{array}$

Level of nicotine dependence by total score:

$0-2=$ low

3-4 = moderate

$5-6=$ high

Based on information in reference 4.

The Heaviness of Smoking Index is a simple way to assess the level of nicotine dependence dividualized based on the severity of nicotine dependence and the probability of developing withdrawal symptoms, as well as on comorbidities, local resources, and patient preferences. ${ }^{3}$

Pharmacotherapy for tobacco treatment is based on alleviating symptoms of nicotine withdrawal with nicotine replacement therapy (NRT) and on optimal use of medications such as varenicline and bupropion. The best results are obtained when pharmacotherapy is combined with behavioral interventions. ${ }^{3}$

\section{EVALUATION OF NICOTINE DEPENDENCE}

The severity of nicotine dependence, risk of developing withdrawal symptoms, and risk of relapse should be determined. The Heaviness of Smoking Index is a simple and validated test to assess the strength of a smoker's nicotine dependence. It consists of 2 questions, making it a quick and practical tool to administer ( Table 1). ${ }^{4}$ Other indicators of nicotine dependence include early initiation of tobacco use, difficulty attaining prolonged abstinence from smoking, history of withdrawal symptoms, and continued use despite knowledge of harm.
Nondaily smokers may use cigarettes compulsively in certain situations but may not have withdrawal symptoms. Factors that influence the risk of relapse include the degree of motivation to quit, presence of comorbid psychiatric disorders, other substance use (eg, heavy alcohol use), and living with other smokers. Nondaily smokers should be advised to quit smoking completely and should be offered assistance to do so. The need for pharmacotherapy should be evaluated on a caseby-case basis.

On the other hand, daily smokers with high nicotine dependence benefit from combination therapies including pharmacotherapy and behavioral interventions.

\section{BEHAVIORAL INTERVENTIONS}

Behavioral support can be provided in faceto-face meetings, group sessions, and text messages. It is typically provided by specialists in tobacco cessation counseling. Interventions that combine pharmacotherapy and behavioral support increase tobacco cessation rates compared with minimal intervention or usual care. ${ }^{5,6}$ Intensive support, especially when it involves in-person contact, increases the chance of abstinence by about $10 \%$ to $20 \%$.

\section{Advice and counseling}

Providing advice about quitting is the most common form of behavioral intervention. Even a brief verbal exchange can increase cessation rates. ${ }^{8}$ Ideally, the advice should be tailored to individual circumstances.

Self-help materials with additional advice and information may also be beneficial. Standardized, print-based, self-help materials increase quit rates compared with no intervention. ${ }^{9}$ However, individual counseling is more effective than self-help materials in promoting smoking cessation, and a more intensive counseling intervention is more effective than a less intensive intervention. ${ }^{10}$ Table 2 lists messages that can be used when giving advice to quit.

\section{Motivational interviewing}

Motivational interviewing is a more intense form of behavioral intervention, ${ }^{11}$ though less commonly used due to lack of knowledge or training. The aims are to increase motivation 


\title{
TABLE 2
}

\section{Suggested messages to use when giving advice on tobacco cessation}

\author{
Brief advice: \\ "Quitting is the best way to improve your health." \\ Develop discrepancy: \\ "How do you think your smoking is affecting your loved ones?" \\ Express empathy: \\ "Many people worry about managing without cigarettes." \\ Manage resistance: \\ "You are worried about how you would manage withdrawal symptoms." \\ Personalized messages: \\ "The best way to prevent lung cancer is to quit smoking." \\ "The best way to prevent another heart attack is to quit smoking." \\ Connect to resources: \\ "There are many effective options. I can help you find the best effective treatment for you." \\ Support self-efficacy: \\ "Would you like information about the benefits and strategies of quitting?"
}

in smokers who do not intend to quit, to enhance self-control over smoking behavior, and to assist in structuring a plan and techniques to control urges and cues.

Motivational interviewing is a collaborative, patient-focused counseling technique. It is designed to help people to explore and resolve ambivalence about behavior change. ${ }^{11}$

\section{Group therapy or classes}

Group therapy or classes offer individuals the opportunity to learn behavioral techniques and provide them with mutual support. ${ }^{12}$

\section{FIRST-LINE THERAPEUTICS}

\section{Nicotine replacement therapy}

NRT delivers nicotine in place of smoking or tobacco use to reduce the urge to smoke, as well as associated withdrawal symptoms. ${ }^{13}$

Clinical guidelines recommend NRT as a first-line treatment for tobacco cessation. ${ }^{14}$ All commercially available forms (gum, transdermal patch, nasal spray, inhaler, and lozenges) are effective in helping smokers increase their chance of quitting successfully. ${ }^{15}$ Each product has about the same efficacy, increasing quit rates by $50 \%$ to $70 \%$ compared with placebo. However, NRT is most effective when the nicotine patch is used in conjunc- tion with a more rapidly absorbed form of NRT (eg, gum). ${ }^{15}$

In the United States, nicotine replacement products are available over the counter or by prescription (Table 3). The initial dosing of most products is based on the number of cigarettes smoked daily or on the time to the first cigarette after waking.

Nicotine patches deliver nicotine in a sustained manner throughout the day. ${ }^{16}$ More rapidly absorbed forms of NRT such as gum, lozenges, inhalers, and spray relieve withdrawal symptoms more quickly than patches. None of the available nicotine delivery systems reproduces the rapid and high levels of arterial nicotine achieved when cigarette smoke is inhaled. ${ }^{16}$ This partially explains why nicotine replacement does not completely eliminate the symptoms of withdrawal. A rapid-release of nicotine gum has been formulated and may achieve faster withdrawal relief. ${ }^{17,18}$

In general, NRT is recommended for 2 to 3 months after smoking cessation. However, it may be used through the period when patients are at high risk for relapse. Some smokers may need to use nicotine replacement products indefinitely. There is no evidence to show that gradual withdrawal of NRT is better than abrupt withdrawal.
Motivational interviewing is a collaborative, patient-focused counseling technique 
TABLE 3

\section{First-line pharmacologic options for tobacco cessation}

\section{Drug, available doses}

Nicotine patch (7 mg, $14 \mathrm{mg}$, $21 \mathrm{mg}$ )

Nicotine gum

(2 mg, $4 \mathrm{mg}$ )

Nicotine lozenge (2 mg, $4 \mathrm{mg}$ )

Nicotine inhaler (10 mg/cartridge)

Puff into mouth as needed use 6-16 cartridges per day (at least 6 cartridges per day for the first 3-6 weeks) for up to 12 weeks

$\begin{array}{ll}\text { Nicotine nasal } & \text { Use } 1 \text { spray in each nostril } \\ \text { spray } & 1-2 \text { times per hour }\end{array}$

(10 mg/mL)

\section{Dosing}

$\leq 10$ cigarettes/day: start with nicotine patch 14 $\mathrm{mg} /$ day

$>10$ cigarettes/day: start with nicotine patch 21 mg/day

\section{Smok} use $2 \mathrm{mg}$

Smokers smoke within 30 min of waking: use $4 \mathrm{mg}$

Smokers wait > 30 min after waking to smoke:

Smokers smoke within 30 min of waking: use $4 \mathrm{mg}$ $1-2$ times per hour day.

Adjust dose as needed based in response.

Begin at least 1-2 weeks before target quit date. maintenance.

Varenicline (0.5 mg, $1 \mathrm{mg}$ )

Days 1-3: $0.5 \mathrm{mg}$ once daily

Days 4-7: $0.5 \mathrm{mg}$ twice daily

Day 8 and later: $1 \mathrm{mg}$ twice daily

\section{Common side effects}

Skin irritation

Insomnia

Vivid dreams

Mouth irritation

Esophageal and

gastric irritation

Hiccups

Jaw pain

Nausea/vomiting

Excess salivation

Headache

Palpitations
Avoid acidic beverages (eg, coffee, carbonated drinks) 15 minutes before and during gum use, as they reduce nicotine absorption.
Gradually reduce dose after 12 weeks.

May use longer than 12 weeks if needed for

Consider combination therapy, discontinuation, or alternative agent if no progress is made by seventh week.

Mouth irritation Mouth ulcers Abdominal pain Hiccups Nausea/vomiting Diarrhea

Headache Palpitations

Mouth irritation Throat irritation Cough

Gradually reduce dose over 6-12 weeks

Treatment should be continued for 12 weeks but can be extended.

Consider dose reduction if usual dose is not tolerated.

Side effects are throat irritation, cough, rhinitis)

Insomnia Headache Dizziness Diaphoresis Weight loss Xerostomia Nausea/vomiting

Insomnia Nausea/vomiting

Abnormal dreams Headache
Do not chew lozenge.

Avoid acidic beverages (eg, coffee, carbonated drinks) 15 minutes before and during gum use, as they reduce nicotine absorption.

Required frequent use.

Each cartridge lasts about 20 minutes if continuously puffing.

Inhaled nicotine may cause bronchospasm. common (headache

Provides a more rapid rise in plasma nicotine concentration than that produced by agents absorbed via the oral mucosa.

Nasal irritation may be a reason to stop. Nasopharyngitis Xerostomia
Consider lowering dose to $150 \mathrm{mg}$ daily if full dose not tolerated.

Decreases seizure threshold.

Varenicline does not increase the risk of depression suicidal ideation, or cardiovascular disease.

${ }^{a}$ Nicotine replacement therapy is recommended for 2 to 3 months after smoking cessation. However, it may be used through the period when the patient is at high risk for relapse. Some smokers may need to use nicotine replacement products indefinitely. 
Side effects of nicotine replacement products include nausea, vomiting, abdominal pain, diarrhea, headache, and local irritation depending on the delivery method. ${ }^{13}$ These can be managed by titrating or changing products. Long-term use is not associated with any serious harmful effects, and the risk of dependence on nicotine replacement products is small. ${ }^{13}$

\section{Bupropion}

Bupropion is an antidepressant. Its mechanism of action in the treatment of nicotine dependence is not well understood. ${ }^{19}$ The main hypothesized effect is the attenuation of withdrawal symptoms (eg, irritability, anxiety) by mimicking nicotinic effects on dopamine and noradrenaline receptors. ${ }^{20}$

Sustained-release bupropion is an effective aid to help smokers quit with or without depression. ${ }^{21}$ It is effective as monotherapy and comparable to the nicotine patch in efficacy. ${ }^{3,22}$ However, the combination of bupropion with NRT is more effective than bupropion or NRT alone. ${ }^{23}$

Bupropion is typically started 1 to 2 weeks before a patient's planned quit date, at a dose of $150 \mathrm{mg}$ daily. After 3 days, the dose should be increased to $150 \mathrm{mg}$ twice daily for 7 to 12 weeks. After this period, bupropion can be continued for up to 12 months, as long as abstinence is attained (maintenance dosage 300 $\mathrm{mg} /$ day). ${ }^{14}$

Common side effects are insomnia (decreased if medication given at least 8 hours before bedtime), headache, dizziness, diaphoresis, weight loss, xerostomia, nausea and vomiting, and pharyngitis. ${ }^{24}$ There is no increase in the incidence of neuropsychiatric adverse events with bupropion compared with placebo in psychiatric and nonpsychiatric cohorts. ${ }^{21}$

Bupropion is contraindicated in patients with seizure disorder and high-risk conditions such as brain arteriovenous malformation, severe head injury, severe stroke, and central nervous tumor or infection. Other contraindications include the presence of anorexia or bulimia; abrupt discontinuation of ethanol; current use of benzodiazepines, barbiturates, or antiepileptic drugs; use of monoamine oxidase inhibitors in the previous 2 weeks; and as concomitant use of linezolid or intravenous methylene blue, a reversible monoamine oxidase inhibitor.

\section{Varenicline}

Varenicline is a partial agonist on 2 nicotinic acetylcholine receptors. ${ }^{25,26}$ These receptors mediate the release of dopamine, the main neurotransmitter underlying nicotine addiction. The partial agonist action decreases the intensity of withdrawal symptoms. It also reduces nicotine binding to nicotinic acetylcholine receptors that generates rewarding effects, thus reducing the perceived pleasure generated by nicotine consumption. This explains why patients on this medication reduce their cigarette consumption even before their quit date. ${ }^{14}$

Although it is recommended to start varenicline dosing at least 1 to 2 weeks before the target quit date (the "fixed target quit date" approach), other approaches are acceptable:

- Medication preloading: ie, starting pharmacotherapy while the smoker is still smoking

- Flexible quit date: patient chooses a quit date within 1 month of starting medication

- Reduce-to-quit approach: gradual smoking reduction with the goal of eventually quitting completely. ${ }^{27}$

Dosing titration starts with $0.5 \mathrm{mg}$ orally once daily for 3 days, with up-titration every 3 days to $1 \mathrm{mg}$ orally twice daily until the end of treatment. In patients who develop adverse effects, lower doses of varenicline (eg, $0.5 \mathrm{mg}$ twice daily) can be used. If well tolerated, varenicline may be used up to 6 months for continued abstinence. ${ }^{28}$

Efficacy. Varenicline is effective in helping smokers achieve tobacco abstinence. It is superior to placebo, bupropion, and NRT.29 Clinical guidelines recommend varenicline as first-line treatment in conjunction with behavioral therapy for a minimum of 12 weeks. $3,14,30$ It may be used in combination with NRT to achieve higher rates of abstinence. ${ }^{31}$

The additive efficacy of combining varenicline and NRT may be due to the partial agonism of individual drugs leading to synergistic effects when combined, or to NRT binding to different or additional receptors not stimulat-
Bupropion is an effective aid to tobacco cessation in smokers with or without depression 
ed by varenicline. It is also possible that shortacting nicotine replacement products add to the effect by allowing as-needed dosing and relief of withdrawal symptoms. ${ }^{32}$

Contraindications are a history of severe hypersensitivity reactions and skin reactions to varenicline. Seizure disorder is not a contraindication, though occurrence of seizures during therapy warrants medication cessation.

Common side effects of varenicline use are nausea, insomnia, abnormal dreams, headache, nasopharyngitis, and xerostomia. ${ }^{21}$

Postmarketing reports of neuropsychiatric adverse effects have included suicidal ideation and behavior, completed suicide, changes in mood, psychosis, aggression, and hostility; these have been reported in smokers with and without previous psychiatric conditions, prompting drug label warnings in many countries. ${ }^{33,34}$ Observational studies, randomized clinical trials, and meta-analyses have not confirmed these concerns, leading the US Food and Drug Administration to remove the boxed warning in 2015 for both varenicline and bupropion. ${ }^{34,35}$

In summary, varenicline does not increase

Preoperative counseling and nicotine replacement therapy can improve surgical outcomes the risk of depression, suicidal ideation, or cardiovascular disease. ${ }^{36,37}$

\section{SECOND-LINE THERAPEUTICS}

Nortriptyline and clonidine are second-line pharmacotherapies. Nortriptyline is a tricyclic antidepressant that has a beneficial effect in smoking cessation..$^{38}$ As with bupropion, its effect on smoking cessation is unrelated to its antidepressant activity. It should be used carefully in patients with chronic heart disease due to potential for QT-segment prolongation. ${ }^{19,38}$

Clonidine is a selective alpha-adrenergic receptor agonist used to treat hypertension. It has been used off-label to treat withdrawal symptoms due to its effect in the central nervous system. It is effective for smoking cessation when compared with placebo, but side effects such as dry mouth and sedation limit its use. ${ }^{19,39}$

It is not clear whether one second-line therapy is more effective than the other. Second-line therapies can be considered when first-line treatments fail or are contraindicated.

\section{DRUG INTERACTIONS}

When prescribing a tobacco cessation drug, it is important to consider the potential for drug interactions (Table 4).24,40,41

\section{Nicotine}

Nicotine from NRT is generally absorbed more slowly and gradually than nicotine from cigarettes, leading to lower nicotine blood levels. ${ }^{42}$ Nicotine may cause tachycardia regardless of the source, so it is possible that nicotine could enhance the tachycardic effect of certain drugs with similar effects on heart rate, such as adenosine..$^{43}$ Drugs that inhibit cytochrome P450 enzymes (eg, cimetidine), which participate in nicotine metabolism, could decrease the clearance of nicotine, thereby increasing the physiologic effects of nicotine. ${ }^{44}$

\section{Varenicline}

Because varenicline is a substrate of the kidney transport protein organic cation transporter 2 (OCT2), medications that inhibit OCT2 could increase the serum concentration of varenicline and therefore increase the risk for adverse effects, especially in patients with renal disease. ${ }^{24}$

Neuropsychiatric adverse effects such as aggressive behavior and amnesia have been reported with the combination of alcohol and varenicline. ${ }^{33}$ Because varenicline may increase the intoxicating effect of alcohol, patients should be counseled to reduce their alcohol intake while on varenicline until they know how varenicline affects their alcohol tolerance. ${ }^{33}$

\section{Bupropion}

Bupropion should not be prescribed for tobacco cessation in patients taking drugs that lower the seizure threshold. The combination may enhance neuroexcitatory effects, thereby increasing the risk of seizures. ${ }^{40}$ Alcohol should be used with caution in patients taking bupropion: it not only lowers the seizure threshold, but also may reduce alcohol tolerance. Patients should be advised to minimize or avoid alcohol consumption while taking bupropion. ${ }^{40}$

Bupropion is a strong inhibitor of the enzyme cytochrome P450 2D6 (CYP2D6), which increases the concentration of drugs that are CYP2D6 substrates and the risk for 


\title{
TABLE 4
}

\section{Drug interactions to consider in tobacco cessation treatment}

\author{
Agent Potential drug interactions \\ Nicotine Adenosine, cimetidine, varenicline \\ replacement \\ therapies \\ Varenicline Alcohol, nicotine, OCT2 inhibitors (eg, histamine-2-receptor blockers, quinolones, tafeno- \\ quine, trimethoprim) \\ Bupropion Drugs that lower seizure threshold (eg, alcohol, selective serotonin reuptake inhibitors, \\ tricyclic antidepressants, systemic steroids) \\ CYP2D6 substrates (eg, aripiprazole, atomoxetine, brexpiprazole, clozapine, codeine, \\ duloxetine, fesoterodine, galantamine, hydrocodone, iloperidone, metoprolol, meto- \\ clopramide, nebivolol, pimozide, primaquine, selective serotonin reuptake inhibitors, \\ tamoxifen, tamsulosin, thioridazine, tramadol, tricyclic antidepressants, valbenazine, \\ vortioxetine) \\ Dopaminergic medications (eg, amantadine, levodopa) \\ CYP2B6 inducers (eg, carbamazepine, efavirenz, nelfinavir, nevirapine, phenobarbital, \\ phenytoin, primidone, rifampin, ritonavir) \\ CYP2B6 inhibitors (eg, clopidogrel, mifepristone; ticlopidine) \\ Digoxin, monoamine oxidase inhibitors
}

Cigarette smoke CYP1A2 substrates (eg, clozapine, fluvoxamine, olanzapine, tacrine, theophylline)

OCT2 = organic cation transporter 2

Based on information in references 24,43 , and 49 .

adverse effects for many of these agents. ${ }^{43}$ However, certain CYP2D6 substrates such as codeine, tramadol, hydrocodone, and tamoxifen rely on CYP2D6 for the metabolic conversion of these drugs to their active metabolites. ${ }^{45,46}$ Concurrent use of bupropion may lead to an inadequate therapeutic response to these agents that are activated by CYP2D6.

Bupropion is contraindicated in patients taking monoamine oxidase inhibitors, which can enhance the hypertensive effect of bupropion. These drugs should not be used concomitantly or within 14 days of one another. ${ }^{47}$

Selective serotonin reuptake inhibitors. Reports suggest that concurrent use of selective serotonin reuptake inhibitors with bupropion may increase the risk for serious toxicity such as serotonin syndrome; however, the mechanism is unclear because the antidepressant effects of bupropion are largely dopamine-based, with less-pronounced effects on serotonin activity. ${ }^{48}$ Antiparkinson agents may enhance the adverse effects of bupropion through cumulative dopamine agonist effects.

Patients taking bupropion for tobacco cessation who are currently taking other dopaminergic agents should be monitored for evidence of central nervous system toxicities such as restlessness, agitation, tremor, ataxia, gait disturbance, vertigo, and dizziness. ${ }^{40}$

Digoxin. Bupropion may decrease the serum concentration of digoxin. Thus, digoxin levels should be monitored if these drugs are used concomitantly.

Finally, drugs that inhibit or induce CYP2B6, the major enzyme involved in the metabolism of bupropion, can interact with bupropion by increasing or decreasing its concentration, respectively. ${ }^{24}$

\section{Effects on drug metabolism after quitting}

In addition to considering the potential drug
Bupropion may lower serum digoxin levels; monitor digoxin levels if these drugs are used concomitantly 
interactions between a selected smoking cessation product and a patient's current medications, it is also important to note that successful smoking cessation can alter the metabolism of medications once the effects of cigarette smoke are eliminated.

Tobacco smoke is known to induce cytochrome P450 enzymes, particularly CYP1A2. Therefore, smokers more rapidly metabolize certain medications that are substrates of this enzyme. ${ }^{41,49}$ When tobacco use ceases, the concentration of these drugs can increase, raising the potential for adverse drug events.

Clozapine, olanzapine, and theophylline may cause clinically significant adverse effects upon smoking cessation, including seizures with clozapine, extrapyramidal effects with olanzapine, and tachycardia with theophylline. ${ }^{49,50}$ Thus, it is important to closely monitor patients taking these drugs when they quit smoking and adjust the dosage.

\section{OTHER INTERVENTIONS}

\section{Smart phone app-based interventions}

The widespread use of smart phones and the advent of health-related apps have the poten-

Phone apps may encourage adherence to treatment, but most do not follow current guidelines on smoking cessation tial to make smoking cessation interventions more accessible. Smart phone apps offer the opportunity to provide tailored behavioral support and real-time responses to smoking urges and cues. ${ }^{51}$ They may help adolescents and young adults adhere to treatment. However, there are concerns regarding their quality and effectiveness, ${ }^{52,53}$ as most apps do not follow existing smoking-cessation treatment guidelines, and the quality of the content is variable. $^{51,53,54}$

While apps could be a successful strategy for specific patients, evidence is lacking to support their use as monotherapy, and they should not replace interventions known to be effective. More research and innovation are needed to evaluate the role and efficacy of mobile apps as a smoking cessation intervention.

\section{Alternative interventions}

Hypnotherapy is widely promoted as a method for aiding smoking cessation. However, there is currently insufficient evidence to determine whether hypnotherapy is effective..$^{55}$ Electrostimulation is not effective for smoking cessation. ${ }^{.6}$
Acupuncture is promoted as a treatment for smoking cessation that can control withdrawal symptoms. ${ }^{56}$ Acupuncture combined with counseling and an educational smoking cessation program may be beneficial..$^{57}$ However, there is very limited high-quality evidence to support acupuncture as monotherapy in smoking cessation. ${ }^{56}$ Well-designed research into these alternative therapies is necessary, especially since these are popular interventions.

\section{OPPORTUNITIES TO ENCOURAGE TOBACCO CESSATION}

\section{Pregnancy}

Female patients of childbearing age and pregnant patients represent an opportunity for clinicians to encourage smoking cessation. All pregnant patients should be counseled to quit. Patients should be counseled about the adverse effects of tobacco use and about effects such as subfertility and miscarriage risks. ${ }^{58,59}$

The American College of Obstetricians and Gynecologists recommends that NRT be considered for pregnant women with a strong resolution to quit. Bupropion is also a reasonable first-line therapy ${ }^{60}$ However, there is limited evidence supporting the subsequent addition of bupropion in patients as a first-line treatment in female patients unable to tolerate NRT or as an addition to counseling and NRT. Varenicline is typically not used in this setting due to the limited data supporting its safety. ${ }^{60}$

\section{Inpatients}

Hospital admission requires temporary tobacco abstinence, providing an opportunity to initiate treatment. The primary reason for hospitalization may serve as an opportunity to provide personalized advice and motivation to quit, especially if surgery is undertaken during the same admission. ${ }^{61}$

Smokers are far more likely to quit if they are provided close follow-up after inpatient discharge (eg, during follow-up appointments) vs traditional provision of postdischarge pharmacotherapy and recommendations alone. ${ }^{62}$

\section{Cardiovascular disease}

The increased risk of cardiovascular disease from tobacco use is well known. In patients 
with known atherosclerotic cardiovascular disease, the approach to tobacco cessation is the same as for patients without cardiovascular disease. Data show that NRT, bupropion, and varenicline do not significantly increase the risk of adverse cardiovascular events. ${ }^{63}$

The lack of evidence regarding the efficacy and safety of NRT in acute coronary syndrome and the theoretical concern for nicotine's vasoconstrictive properties may explain why clinicians tend to avoid recommending it. However, NRT is a first-line therapy for the relief of withdrawal symptoms in inpatients with acute coronary syndrome, according to expert consensus. ${ }^{14}$ NRT or varenicline can be prescribed at hospital discharge. ${ }^{14}$

\section{Preoperative evaluation}

Because cigarette smoking increases the risk for poor postoperative outcomes, formal preoperative counseling and use of NRT are recommended because they result in greater rates of preoperative cessation and lower rates of postoperative complications than no treatment. ${ }^{64}$

Concerns that quitting shortly before surgery could increase the risk of pulmonary complications have been found to be unsubstantiated. ${ }^{65}$ Patients should be advised to quit at any time before surgery. Although the optimal duration of abstinence is not known, a greater reduction in risk of complications is associated with longer periods of abstinence. ${ }^{66}$ As with hospitalized patients undergoing surgical procedures, postdischarge cessation rates were found to be highest in those who received formal perioperative counseling and pharmacotherapy. ${ }^{67}$

\section{Psychiatric and mental health considerations}

Nicotine dependence is known to exacerbate concurrent mental illnesses and psychiatric disorders. However, patients with psychiatric needs are less likely to be provided with tobacco cessation counseling or pharmacotherapy. ${ }^{68}$ Recent studies have shown that the safety of NRT, varenicline, and bupropion are comparable between patients with and without psychiatric disorders. ${ }^{21}$ It is reasonable to offer varenicline and NRT alongside formal tobacco cessation counseling, followed by use of bupropion as a second-line agent in the ab- sence of a documented seizure history. ${ }^{69}$

\section{ELECTRONIC CIGARETTES}

E-cigarettes have been proposed as a method to reduce the harms of tobacco use and as a nicotine replacement product. ${ }^{70}$ However, ecigarettes can also cause nicotine dependence, so users may need treatment for nicotine dependence similar to that for tobacco users. ${ }^{71}$

\section{Studies in tobacco cessation}

E-cigarettes have been promoted as safe alternatives to combustible cigarettes, and they have been studied in randomized controlled trials as a treatment for tobacco cessation. ${ }^{72}$

One randomized trial compared nicotinecontaining e-cigarettes with NRT. ${ }^{72}$ The ecigarette group abstinence rate was $18 \%$ at 12 months, though $80 \%$ continued use of e-cigarettes, compared with a $9 \%$ abstinence rate in the NRT group and a $9 \%$ rate of continued use of NRT. ${ }^{72}$

Although e-cigarettes were beneficial in achieving abstinence, the concern is that individuals continued to use them. It is not clear whether e-cigarettes truly reduce harm as they are not as safe as they are promoted to be. While nicotine inhalation with e-cigarettes is thought to release fewer toxic by-products than combustible cigarettes, there are concerns regarding their safety. ${ }^{73}$ Carcinogens and toxins have been found in the liquid used for vaporization and in the aerosols emitted, and e-cigarettes have been associated with an outbreak of cases of acute lung injury that caused hospitalizations and even deaths. ${ }^{74,75}$

The long-term consequences are unknown, but several studies have shown the potential of e-cigarettes to cause chronic lung and heart disease and to increase the risk of infection and of cancer. ${ }^{76}$

The potential for nicotine addiction with e-cigarettes is also concerning. Pod systems (eg, JUUL brand) are popular devices that can deliver high concentrations of nicotine through the use of nicotine salts. ${ }^{77,78}$ For example, each JUUL pod may contain a nicotine concentration of $3 \%$ (equivalent to 35 $\mathrm{mg} / \mathrm{mL}$ ) or $5 \%$ (equivalent to $59 \mathrm{mg} / \mathrm{mL}$ ). ${ }^{79}$ A combustible cigarette has a nicotine concentration between $1.5 \%$ and $2 \% .{ }^{80}$ It is worrisome that e-cigarette users are often unaware

\section{Several studies have shown the potential of e-cigarettes to cause chronic lung and heart disease and to increase risk of infection and cancer}


of or underestimate the nicotine content. ${ }^{81,82}$

\section{Managing nicotine dependence related to e-cigarettes}

It is not clear whether nicotine dependence from e-cigarette use should be managed differently than that from combustible cigarette smoking. Because the addiction is to the same substance, it is likely that the same strategies and tools could be applied with careful attention to the unique aspects of e-cigarette use.

The pattern of use with e-cigarettes is different. An e-cigarette does not need to be lit; it can be used any time and with a potentially higher frequency than combustible cigarettes; and nicotine concentrations can be higher in e-cigarettes. Thus, this pattern of use can pose a higher risk of withdrawal symptoms.

This highlights the need for clinicians to familiarize themselves with different e-cigarette products and their nicotine content, as well as the need for further investigation into whether higher doses of NRT are necessary in these patients.

\section{E-cigarettes use by adolescents: A public health concern}

Another important aspect is the high prevalence of e-cigarette use among adolescents. Adolescent e-cigarette usage is now a major public health concern, with 1 in every 6 high school students reporting current e-cigarette use. 83,84

Treatment options for adolescents are more limited than those for adults. Neither varenicline nor bupropion has shown benefit in the adolescent population based on limited studies of nicotine dependence associated with combustible cigarettes. ${ }^{85}$ NRT combined with cognitive-behavioral interventions has been shown to be effective in adolescent cigarette smokers. ${ }^{86}$ However, further research is needed to determine the most effective treatment of nicotine dependence in adolescents, especially when it is associated with e-cigarette use.

\section{THE BOTTOM LINE}

Nicotine dependence is a chronic relapsing disease. Every tobacco user should be offered treatment for tobacco cessation regardless of their level of readiness to quit.

Treatment should be based on the severity of nicotine dependence, the probability of developing withdrawal symptoms, risk of relapse, comorbidities, local resources, and patient preferences.

Comprehensive tobacco treatment that combines pharmacologic and behavioral therapy significantly increases successful tobacco cessation. Although there are many popular alternative treatments, they should not replace or delay the use of known effective therapies.

E-cigarettes have been proposed as a method of reducing the harms of tobacco use, but they also can cause nicotine addiction. Moreover, their effectiveness in tobacco cessation treatment has not been determined, and concerns related to their safety preclude their use in tobacco cessation treatment at this time.

\section{DISCLOSURES}

The authors report no relevant financial relationships which, in the context of their contributions, could be perceived as a potential conflict of interest.

\section{REFERENCES}

1. Centers for Disease Control. 2014 Surgeon General's report: the health consequences of smoking - 50 years of progress. www.cdc. gov/tobacco/data_statistics/sgr/50th-anniversary/index.htm. Accessed May 26, 2021.

2. Creamer MR, Wang TW, Babb S, et al. Tobacco product use and cessation indicators among adults-United States, 2018. MMWR Morb Mortal Wkly Rep 2019; 68(45):1013-1019. doi:10.15585/mmwr.mm6845a2

3. Clinical Practice Guideline Treating Tobacco Use and Dependence 2008 Update Panel, Liaisons, and Staff. A clinical practice guideline for treating tobacco use and dependence: 2008 update. A US Public Health Service report. Am J Prev Med 2008; 35(2):158-176. doi:10.1016/j.amepre.2008.04.009

4. Heatherton TF, Kozlowski LT, Frecker RC, Rickert W, Robinson J. Measuring the heaviness of smoking: using self-reported time to the first cigarette of the day and number of cigarettes smoked per day.
Br J Addict 1989; 84(7):791-799.

doi:10.1111/j.1360-0443.1989.tb03059.x

5. American Lung Association. Freedom from smoking. http://www. freedomfromsmoking.org/. Accessed May 26, 2021.

6. Stead LF, Koilpillai P, Fanshawe TR, Lancaster T. Combined pharmacotherapy and behavioural interventions for smoking cessation. Cochrane Database Syst Rev 2016; 3:CD008286.

doi:10.1002/14651858.CD008286.pub3

7. Hartmann-Boyce J, Hong B, Livingstone-Banks J, Wheat H, Fanshawe TR. Additional behavioural support as an adjunct to pharmacotherapy for smoking cessation. Cochrane Database Syst Rev 2019; 6(6):CD009670. doi:10.1002/14651858.CD009670.pub4

8. Russell MA, Wilson C, Taylor C, Baker CD. Effect of general practitioners' advice against smoking. Br Med J 1979; 2(6184):231-235. doi:10.1136/bmj.2.6184.231

9. Hartmann-Boyce J, Lancaster T, Stead LF. Print-based self-help interventions for smoking cessation. Cochrane Database Syst Rev 2014; (6):CD001118. doi:10.1002/14651858.CD001118.pub3 


\section{CHOI AND COLLEAGUES}

10. Lancaster T, Stead LF. Individual behavioural counselling for smoking cessation. Cochrane Database Syst Rev 2017; 3(3):CD001292. doi:10.1002/14651858.CD001292.pub3

11. Lindson N, Thompson TP, Ferrey A, Lambert JD, Aveyard P. Motivational interviewing for smoking cessation. Cochrane Database Syst Rev 2019; 7(7):CD006936. doi:10.1002/14651858.CD006936.pub4

12. Stead LF, Carroll AJ, Lancaster T. Group behaviour therapy programmes for smoking cessation. Cochrane Database Syst Rev 2017; 3(3):CD001007. doi:10.1002/14651858.CD001007.pub3

13. Drug and Therapeutics Bulletin. Republished: nicotine and health. BMJ 2014; 349:2014.7.0264rep. doi:10.1136/bmj.2014.7.0264rep

14. Barua RS, Rigotti NA, Benowitz NL, et al. 2018 ACC expert consensus decision pathway on tobacco cessation treatment: a report of the American College of Cardiology task force on clinical expert consensus documents. J Am Coll Cardiol 2018; 72(25):3332-3365. doi:10.1016/j.jacc.2018.10.027

15. Stead LF, Perera R, Bullen C, et al. Nicotine replacement therapy for smoking cessation. Cochrane Database Syst Rev 2012; 11:CD000146. doi:10.1002/14651858.CD000146.pub4

16. Henningfield JE. Nicotine medications for smoking cessation. N Engl J Med 1995; 333(18):1196-1203. doi:10.1056/NEJM199511023331807

17. Shiffman S, Cone EJ, Buchhalter AR, et al. Rapid absorption of nicotine from new nicotine gum formulations. Pharmacol Biochem Behav 2009; 91(3):380-384. doi:10.1016/j.pbb.2008.08.012

18. Niaura R, Sayette M, Shiffman S, et al. Comparative efficacy of rapid-release nicotine gum versus nicotine polacrilex gum in relieving smoking cue-provoked craving. Addiction 2005; 100(11):1720-1730. doi:10.1111/j.1360-0443.2005.01218.x

19. Gómez-Coronado N, Walker AJ, Berk M, Dodd S. Current and emerging pharmacotherapies for cessation of tobacco smoking. Pharmacotherapy 2018; 38(2):235-258. doi:10.1002/phar.2073

20. Warner C, Shoaib M. How does bupropion work as a smoking cessation aid? Addict Biol 2005; 10(3):219-231. doi:10.1080/13556210500222670

21. Anthenelli RM, Benowitz NL, West R, et al. Neuropsychiatric safety and efficacy of varenicline, bupropion, and nicotine patch in smokers with and without psychiatric disorders (EAGLES): a doubleblind, randomised, placebo-controlled clinical trial. Lancet 2016; 387(10037):2507-2520. doi:10.1016/50140-6736(16)30272-0

22. Hurt RD, Sachs DP, Glover ED, et al. A comparison of sustainedrelease bupropion and placebo for smoking cessation. N Engl J Med 1997; 337(17):1195-1202. doi:10.1056/NEJM199710233371703

23. Suissa K, Larivière J, Eisenberg MJ, et al. Efficacy and safety of smoking cessation interventions in patients with cardiovascular disease: a network meta-analysis of randomized controlled trials. Circ Cardiovasc Qual Outcomes 2017; 10(1):e002458. doi:10.1161/CIRCOUTCOMES.115.002458

24. Patel K, Allen S, Haque MN, Angelescu I, Baumeister D, Tracy DK. Bupropion: a systematic review and meta-analysis of effectiveness as an antidepressant. Ther Adv Psychopharmacol 2016;6(2):99-144. doi:10.1177/2045125316629071

25. de Moura FB, McMahon LR. The contribution of alpha-4-beta-2 and non-alpha-4-beta-2 nicotinic acetylcholine receptors to the discriminative stimulus effects of nicotine and varenicline in mice. Psychopharmacology (Berl) 2017; 234(5):781-792. doi:10.1007/s00213-016-4514-4

26. Rollema H, Chambers LK, Coe JW, et al. Pharmacological profile of the alpha4beta2 nicotinic acetylcholine receptor partial agonist varenicline, an effective smoking cessation aid. Neuropharmacology 2007; 52(3):985-994. doi:10.1016/j.neuropharm.2006.10.016

27. Tonstad S, Arons C, Rollema H, et al. Varenicline: mode of action, efficacy, safety and accumulated experience salient for clinical populations. Curr Med Res Opin 2020; 36(5):713-730. doi:10.1080/03007995.2020.1729708

28. Tonstad S, Tønnesen P, Hajek P, et al. Effect of maintenance therapy with varenicline on smoking cessation: a randomized controlled trial. JAMA 2006; 296(1):64-71. doi:10.1001/jama.296.1.64

29. Cahill K, Lindson-Hawley N, Thomas KH, Fanshawe TR, Lancaster T. Nicotine receptor partial agonists for smoking cessation. Cochrane Database Syst Rev 2016; 2016(5):CD006103.
doi:10.1002/14651858.CD006103.pub7

30. Shields PG, Herbst RS, Arenberg D, et al. Smoking cessation, version 1.2016, NCCN clinical practice guidelines in oncology. J Natl Compr Canc Netw 2016; 14(11):1430-1468. doi:10.6004/jnccn.2016.0152

31. Koegelenberg CF, Noor F, Bateman ED, et al. Efficacy of varenicline combined with nicotine replacement therapy vs varenicline alone for smoking cessation: a randomized clinical trial. JAMA 2014; 312(2):155-161. doi:10.1001/jama.2014.7195

32. Chang PH, Chiang CH, Ho WC, Wu PZ, Tsai JS, Guo FR. Combination therapy of varenicline with nicotine replacement therapy is better than varenicline alone: a systematic review and meta-analysis of randomized controlled trials. BMC Public Health 2015; 15:689. doi:10.1186/s12889-015-2055-0

33. US Food and Drug Administration. Drug safety communication: FDA updates label for stop smoking drug Chantix (varenicline) to include potential alcohol interaction, rare risk of seizures, and studies of side effects on mood, behavior, or thinking. https://www.fda.gov/ media/90779/download. Accessed May 26, 2021.

34. US Food and Drug Administration. Drug safety communication. Safety review update of Chantix (varenicline) and risk of neuropsychiatric adverse events. https://www.fda.gov/drugs/drug-safety-andavailability/fda-drug-safety-communication-safety-review-updatechantix-varenicline-and-risk-neuropsychiatric. Accessed May 26, 2021.

35. US Food and Drug Administration. Drug safety communication. FDA revises description of mental health side effects of the stop-smoking medicines Chantix (varenicline) and Zyban (bupropion) to reflect clinical trial findings. https://www.fda.gov/drugs/drug-safety-andavailability/fda-drug-safety-communication-fda-revises-descriptionmental-health-side-effects-stop-smoking. Accessed May 26, 2021.

36. Mills EJ, Thorlund K, Eapen S, Wu P, Prochaska JJ. Cardiovascular events associated with smoking cessation pharmacotherapies: a network meta-analysis. Circulation 2014; 129(1):28-41. doi:10.1161/CIRCULATIONAHA.113.003961

37. Kotz D, Viechtbauer W, Simpson CR, van Schayck OCP, West R, Sheikh A. Cardiovascular and neuropsychiatric risks of varenicline and bupropion in smokers with chronic obstructive pulmonary disease. Thorax 2017; 72(10):905-911. doi:10.1136/thoraxjnl-2017-210067

38. Howes S, Hartmann-Boyce J, Livingstone-Banks J, Hong B, Lindson N. Antidepressants for smoking cessation. Cochrane Database Syst Rev 2020;4(4):CD000031. doi:10.1002/14651858.CD000031.pub5

39. Gourlay SG, Stead LF, Benowitz NL. Clonidine for smoking cessation. Cochrane Database Syst Rev 2004; 2004(3):CD000058. doi:10.1002/14651858.CD000058.pub2

40. Valeant Pharmaceuticals International, Inc. Highlights of prescribing information. Wellbutrin XL. https://www.accessdata.fda.gov/drugsatfda_docs/label/2017/021515s036lbl.pdf. Accessed May 26, 2021.

41. Kroon LA. Drug interactions with smoking. Am J Health Syst Pharm 2007; 64(18):1917-1921. doi:10.2146/ajhp060414

42. Le Houezec J. Role of nicotine pharmacokinetics in nicotine addiction and nicotine replacement therapy: a review. Int J Tuberc Lung Dis 2003; 7(9):811-819. pmid:12971663

43. Smits $\mathbf{P}$, Eijsbouts $\mathbf{A}$, Thien $\mathbf{T}$. Nicotine enhances the circulatory effects of adenosine in human beings. Clin Pharmacol Ther 1989; 46(3):272-278. doi:10.1038/clpt.1989.138

44. Bendayan R, Sullivan JT, Shaw C, Frecker RC, Sellers EM. Effect of cimetidine and ranitidine on the hepatic and renal elimination of nicotine in humans. Eur J Clin Pharmacol 1990; 38(2):165-169. doi:10.1007/BF00265978

45. Caraco Y, Sheller J, Wood AJ. Pharmacogenetic determination of the effects of codeine and prediction of drug interactions. J Pharmacol Exp Ther 1996; 278(3):1165-1174. pmid:8819499

46. Frost DA, Soric MM, Kaiser R, Neugebauer RE. Efficacy of tramadol for pain management in patients receiving strong cytochrome P450 2 D6 inhibitors. Pharmacotherapy 2019; 39(6):724-729. doi:10.1002/phar.2269

47. Marcucci C, Sandson NB, Dunlap JA. Linezolid-bupropion interaction as possible etiology of severe intermittent intraoperative hyperten- 
sion? Anesthesiology 2004; 101(6):1487-1488. doi:10.1097/00000542-200412000-00051

48. Munhoz RP. Serotonin syndrome induced by a combination of bupropion and SSRIs. Clin Neuropharmacol 2004; 27(5):219-222. doi:10.1097/01.wnf.0000142754.46045.8c

49. Chui CY, Taylor SE, Thomas D, George J. Prevalence and recognition of highly significant medication-smoking cessation interactions in a smoke-free hospital. Drug Alcohol Depend 2019; 200:78-81. doi:10.1016/j.drugalcdep.2019.03.006

50. Lowe EJ, Ackman ML. Impact of tobacco smoking cessation on stable clozapine or olanzapine treatment. Ann Pharmacother 2010; 44(4):727-732. doi:10.1345/aph.1M398

51. Hoeppner BB, Hoeppner SS, Seaboyer L, et al. How smart are smartphone apps for smoking cessation? A content analysis. Nicotine Tob Res 2016; 18(5):1025-1031. doi:10.1093/ntr/ntv117

52. Jacobs MA, Cobb CO, Abroms L, Graham AL. Facebook apps for smoking cessation: a review of content and adherence to evidencebased guidelines. J Med Internet Res 2014; 16(9):e205. doi:10.2196/jmir.3491

53. Haskins BL, Lesperance D, Gibbons $P$, Boudreaux ED. A systematic review of smartphone applications for smoking cessation. Transl Behav Med 2017; 7(2):292-299. doi:10.1007/s13142-017-0492-2

54. Rajani NB, Weth D, Mastellos N, Filippidis FT. Adherence of popular smoking cessation mobile applications to evidence-based guidelines. BMC Public Health 2019; 19(1):743. doi:10.1186/s12889-019-7084-7

55. Barnes J, McRobbie H, Dong CY, Walker N, Hartmann-Boyce J. Hypnotherapy for smoking cessation. Cochrane Database Syst Rev 2019; 6(6):CD001008. doi:10.1002/14651858.CD001008.pub3

56. White AR, Rampes H, Liu JP, Stead LF, Campbell J. Acupuncture and related interventions for smoking cessation. Cochrane Database Sys Rev 2014; 2014(1):CD000009. doi:10.1002/14651858.CD000009.pub4

57. Wang JH, van Haselen $\mathbf{R}$, Wang $\mathbf{M}$, et al. Acupuncture for smoking cessation: a systematic review and meta-analysis of 24 randomized controlled trials. Tob Induc Dis 2019; 17:48. doi:10.18332/tid/109195

58. Practice Committee of the American Society for Reproductive Medicine. Practice Committee of the American Society for Reproductive Medicine. Smoking and infertility: a committee opinion. Fertil Steril 2018; 110(4):611-618. doi:10.1016/j.fertnstert.2018.06.016

59. Pineles BL, Park E, Samet JM. Systematic review and meta-analysis of miscarriage and maternal exposure to tobacco smoke during pregnancy. Am J Epidemiol 2014; 179(7):807-823. doi:10.1093/aje/kwt334

60. Committee opinion no. 721 summary: smoking cessation during pregnancy. Obstet Gynecol 2017; 130(4):1. doi:10.1097/AOG.0000000000002348

61. Shi Y, Warner DO. Surgery as a teachable moment for smoking cessation. Anesthesiology 2010; 112(1):102-107. doi:10.1097/ALN.0b013e3181c61cf9

62. Rigotti NA, Regan S, Levy DE, et al. Sustained care intervention and postdischarge smoking cessation among hospitalized adults: a randomized clinical trial. JAMA 2014; 312(7):719-728. doi:10.1001/jama.2014.9237

63. Benowitz NL, Pipe A, West R, et al. Cardiovascular safety of varenicline, bupropion, and nicotine patch in smokers: a randomized clinical trial. JAMA Intern Med 2018; 178(5):622-631. doi:10.1001/jamainternmed.2018.0397

64. Thomsen T, Villebro N, Møller AM. Interventions for preoperative smoking cessation. Cochrane Database Syst Rev 2014; 2014(3):CD002294. doi:10.1002/14651858.CD002294.pub4

65. Shi Y, Warner DO. Brief preoperative smoking abstinence: is there a dilemma? Anesth Analg 2011; 113(6):1348-1351. doi:10.1213/ANE.0b013e31822d6798

66. Mills E, Eyawo O, Lockhart I, Kelly S, Wu P, Ebbert JO. Smoking cessation reduces postoperative complications: a systematic review and meta-analysis. Am J Med 2011; 124(2):144-154.e8. doi:10.1016/j.amjmed.2010.09.013

67. Lee SM, Landry J, Jones PM, Buhrmann O, Morley-Forster P. Longterm quit rates after a perioperative smoking cessation randomized controlled trial. Anesth Analg 2015; 120(3):582-587.
doi:10.1213/ANE.0000000000000555

68. Prochaska JJ. Smoking and mental illness-breaking the link. N Engl J Med 2011; 365(3):196-198. doi:10.1056/NEJMp1105248

69. Zawertailo L. Safety of smoking cessation drugs for mentally ill patients. Lancet 2016; 387(10037):2481-2482. doi:10.1016/S0140-6736(16)30294-X

70. Hartmann-Boyce J, McRobbie H, Bullen C, Begh R, Stead LF, Hajek P. Electronic cigarettes for smoking cessation. Cochrane Database Syst Rev 2016; 9(9):CD010216. doi:10.1002/14651858.CD010216.pub3

71. Grana R, Benowitz N, Glantz SA. E-cigarettes: a scientific review. Circulation 2014; 129(19):1972-1986. doi:10.1161/CIRCULATIONAHA.114.007667

72. Hajek P, Phillips-Waller A, Przulj D, et al. A randomized trial of ecigarettes versus nicotine-replacement therapy. N Engl J Med 2019; 380(7):629-637. doi:10.1056/NEJMoa1808779

73. Oh AY, Kacker A. Do electronic cigarettes impart a lower potential disease burden than conventional tobacco cigarettes? Review on e-cigarette vapor versus tobacco smoke. Laryngoscope 2014; 124(12):2702-2706. doi:10.1002/lary.24750

74. Cheng T. Chemical evaluation of electronic cigarettes. Tob Control 2014; 23(suppl 2):ii11-ii17. doi:10.1136/tobaccocontrol-2013-051482

75. Centers for Disease Control. Outbreak of lung injury associated with the use of e-cigarette, or vaping products. https://www.cdc. gov/tobacco/basic_information/e-cigarettes/severe-lung-disease. html\#what-we-know. Accessed May 26, 2021.

76. Bozier J, Chivers EK, Chapman DG, et al. The evolving landscape of e-cigarettes: a systematic review of recent evidence. Chest 2020; 157(5):1362-1390. doi:10.1016/j.chest.2019.12.042

77. Boykan R, Goniewicz ML, Messina CR. Evidence of nicotine dependence in adolescents who use Juul and similar pod devices. Int J Environ Res Public Health 2019; 16(12):2135. doi:10.3390/ijerph16122135

78. Goniewicz ML, Boykan R, Messina CR, Eliscu A, Tolentino J. High exposure to nicotine among adolescents who use Juul and other vape pod systems ('pods'). Tob Control 2019; 28(6):676-677. doi:10.1136/tobaccocontrol-2018-054565

79. JUUL Labs. Discover more about JUULpods \& flavors. https://www. juul.com/resources/What-is-JUUL-Vape-Juice-All-JUUL-Pod-Flavors. Accessed May 26, 2021

80. Jackler RK, Ramamurthi D. Nicotine arms race: JUUL and the high-nicotine product market. Tob Control 2019; 28(6):623-628. doi:10.1136/tobaccocontrol-2018-054796

81. Morean ME, Bold KW, Kong G, et al. Adolescents' awareness of the nicotine strength and e-cigarette status of JUUL e-cigarettes. Drug Alcohol Depend 2019; 204:107512. doi:10.1016/j.drugalcdep.2019.05.032

82. Pankow JF, Kim K, McWhirter KJ, et al. Benzene formation in electronic cigarettes. PLoS One 2017; 12(3):e0173055. doi:10.1371/journal.pone.0173055

83. Arrazola RA, Singh T, Corey CG, et al. Tobacco use among middle and high school students-United States, 2011-2014. MMWR Morb Mortal Wkly Rep 2015; 64(14):381-385. pmid:25879896

84. Wang TW, Gentzke AS, Creamer MR, et al. Tobacco product use and associated factors among middle and high school students-United States, 2019. MMWR Surveill Summ 2019; 68(12):1-22. doi:10.15585/mmwr.ss6812a1

85. Fanshawe TR, Halliwell W, Lindson N, Aveyard P, LivingstoneBanks J, Hartmann-Boyce J. Tobacco cessation interventions for young people. Cochrane Database Syst Rev 2017; 11(11):CD003289. doi:10.1002/14651858.CD003289.pub6

86. Moolchan ET, Robinson ML, Ernst M, et al. Safety and efficacy of the nicotine patch and gum for the treatment of adolescent tobacco addiction. Pediatrics 2005; 115(4):e407-e414. doi:10.1542/peds.2004-1894

Address: Humberto K. Choi, MD, FCCP, Respiratory Institute, A90, Cleveland Clinic, 9500 Euclid Avenue, Cleveland, OH 44195; choih@ccf.org 